\title{
AUDIT IN THE CONDITIONS OF DIGITAL ECONOMY
}

\author{
Varvara A. Fedorcova \\ Petrozavodsk State University, Petrozavodsk, Russian Federation
}

\begin{abstract}
The article is devoted to the development of audit while applying smart technologies of economy in the digital economy of Russia. The aim of the work is to determine the development of digital audit, which allows timely identification of errors in the process of recording the activities of subjects. It is proposed to introduce the definition of "digital audit". The paper considers the features of conducting and developing digital audit. The author determines the significance of the normative work when regulating digital audit and the need to use a single system of information technologies to increase the efficiency of audits. The main requirements, indicators of digital audit and methods for improving it to assess the activities of entities in accordance with the development program are highlighted. The rationale for the introduction of digital economy in the public and private sectors, in particular the improvement of internal and external auditing, is substantiated. It is necessary to create a digital infrastructure for supporting analytical activities, improving feedback procedures, implementing analytics systems and supporting decision-making based on digital data. It is emphasized that the focus of the control system is the place of audit in the considered connection "goal - means - result". An important aspect of audit is the risk-oriented result aimed at interacting and improving the information exchange of control and accounting bodies of subjects and state (municipal) authorities with the Accounts Chamber of the Russian Federation, at creating a unified anti-corruption system, at increasing mechanisms for preventing crime. The well-developed methodology base allows timely identification and analysis of problems, formation of a rational plan for checking (performing work) and efficiently allocating resources, identifying performers random errors or cases of fraud, and identifying violations during internal procedures. The main indicators of digital audit are analyzed based on the results of the implementation of the strategic development program for 2018-2019.
\end{abstract}

Key words: digital economy, audit, state audit, digital audit, risk oriented result.

Citation. Fedorcova V.A. Audit in the Conditions of Digital Economy. Journal of Volgograd State University. Economics, 2020, vol. 22, no. 2, pp. 193-200. (in Russian). DOI: https://doi.org/10.15688/ek.jvolsu.2020.2.18

УДК 336.2

Дата поступления статьи: 02.03.2020

ББК 65.052 Дата принятия статьи: 16.03.2020

\section{АУДИТ В УСЛОВИЯХ ЦИФРОВОЙ ЭКОНОМИКИ}

\author{
Варвара Александровна Федорцова \\ Петрозаводский государственный университет, г. Петрозаводск, Российская Федерация
}

\begin{abstract}
Аннотация. Статья посвящена развитию аудита при применении умных технологий экономики в системе цифровой экономики России. Целью работы является определить развитие цифрового аудита, позволяющего своевременно выявлять ошибки в процессе учета деятельности субъектов. Предлагается ввести дефиницию «цифровой аудит» (информационный аудит). Рассмотрены особенности проведения и развития цифрового аудита. Определены значимость нормотворчества при регулировании цифрового аудита и необходимость использования единой системы информационных технологий для повышения эффективности проверок. Выделены основные требования, показатели цифрового аудита и методы его совершенствования для оценки деятельности субъектов в соответствии с программой развития. Обоснована необходимость внедрения цифровой экономики в государственный и негосударственный сектор, в частности, совершенствование внутреннего и внешнего аудита. Для этого необходимо создание цифровой инфраструктуры поддержки Өे аналитической деятельности, совершенствование процедур обратной связи, внедрение систем аналитики и (?) поддержки принятия решения, основанных на цифровых данных. Определено место аудита в рассмотренной
\end{abstract}


связи «цель - средство - результат» в системе контроля. Важным является расширение взаимодействия в области информационного обмена контрольно-счетных органов субъектов и органов государственной (муниципальной) власти со Счетной палатой РФ в целях создания единой антикоррупционной системы, направленной на улучшение механизмов предотвращения правонарушений. Выстроенная методологическая база позволяет своевременно выявлять и анализировать проблемы, формировать рациональный план проверки (выполнения работ) и эффективно распределять ресурсы, выявлять случайную ошибку исполнителя или случаи мошенничества, определять нарушения при выполнении внутренних процедур. Проанализированы основные показатели цифрового аудита по итогам выполнения программы стратегического развития за 2018-2019 годы.

Ключевые слова: цифровая экономика, аудит, государственный аудит, цифровой аудит, риск ориентированный результат.

Цитирование. Федорцова В. А. Аудит в условиях цифровой экономики // Вестник Волгоградского государственного университета. Экономика. - 2020. - Т. 22, № 2. - C. 193-200. - DOI: https://doi.org/10.15688/ ek.jvolsu.2020.2.18

\section{Введение}

В условиях применения умных технологий экономики важное место в поддержании общественного контроля общества и государства занимает аудит цифровой экономики субъектов финансово-хозяйственной деятельности.

Выдающиеся ученые-экономисты, такие как А.С. Наринский, Н.Г. Гаджиев, Т.В. Миргородская [Федорцова, 2017, с. 49], определяют важность осуществления «консультационного (советующего) аудита» посредством анализа и мониторинга экономической информации.

Ряд работ зарубежных авторов, таких как P.X. Монтгомери и Дж. Робертсона, посвящены анализу теоретических аспектов развития аудита как независимых инструментов экономической деятельности государства.

Целью аудита является своевременное проведение предварительного, текущего и последующего контроля деятельности предприятия.

Предварительный контроль предупреждает на первичной стадии планирования и проведения финансовых и контрольных мероприятий со стороны государства и внутри хозяйствующего субъекта - незаконные, необоснованные и неэффективные действия. Можно выявить на раннем этапе нецелесообразность и рискованность использования денежных фондов, возможных источников их формирования. Текущие (оперативные) контрольные мероприятия проводятся непосредственно при осуществлении юридических событий, операций, действий и направлены на выявление абсолютных и относительных отклонений финансово-хозяйственной деятельности субъектов. Оперативный контроль позволяет оценить оперативность, достоверность, качество и своевременность поставленных целей и задач субъекта проверки. Важным является отражение операций в момент совершения юридических фактов. Текущие контрольные мероприятия являются ведущими и значимыми для оценки предварительного контроля, заключающегося в планировании (нормировании, бюджетирования) и нормотворчестве. В процессе оперативной деятельности возможна корректировка, предупреждение и профилактика отрицательных юридических фактов. Результативность последующих контрольных мероприятий заключается в проверке не только на соответствие и достоверность, но и на оценку своевременности, эффективности выполнения задания, применения предупредительных мер, рекомендуемых к правомерному действию и исключающих неправовые последствия. Последующий контроль основывается на всестороннем, комплексном анализе показателей финансово-хозяйственной деятельности, что позволяет выявить недостатки предварительного и текущего контроля.

На основе вышеуказанных мероприятий были выделены дефиниции «внешний» и «внутренний» аудит. Они закреплены за различными органами и отличаются целями, но к ним применяются единые методики оценки показателей, что позволит эффективно использовать систему цифрового аудита. 
Внешний аудит в России закреплен за Счетной палатой РФ [Бюджетный кодекс ... ; О Счетной палате ...], основной целью которой является проверка на соответствие обоснованности, действительности, эффективности, целенаправленности, объективности и результативности использования бюджетных средств, реализации национальных проектов стратегического социально-экономического развития страны как в публичном, так и частном секторе независимо от правового статуса субъектов. В настоящее время на первое место в ходе проверок ставится именно стратегическое планирование, соответственно, важен не только аудит за текущий или прошедший период, но и стратегический аудит.

В процессе деятельности предприятий используют множество информационных технологий, что позволяет выделить дефиницию «цифровой аудит» [Счетная палата ...] в системе цифровой экономики. В частности, на развитие цифрового аудита влияет электронный бюджет и налоговый мониторинг, позволяющий своевременно выявлять ошибки в процессе учета деятельности субъектов.

На развитие цифрового аудита прежде всего влияет законотворческая деятельность в области аудита в России. Нельзя сказать, что законодательство в сфере государственного аудита решило все проблемы. Очевидно, что нормотворчество не всегда охватывает все особенности развития цифрового аудита в системе цифровой экономики. Предстоит большая работа по разработке и закреплению методики использования новых технологий аудита как в нормативных актах Счетной палаты, так и в рабочих документах аудитора (ревизора).

\section{Результаты исследования}

Электронный бюджет, позволяет своевременно анализировать показатели результативности, что усиливает профилактику финансовых правонарушений. Для повышения эффективности цифрового аудита необходимо, чтобы государственные (муниципальные) и частные субъекты использовали единую систему информационных технологий. В частности, используются информационные технологии представленные компаниями «Фирма
“1C"», «Контур» программ 1С: Бухгалтерия и $1 \mathrm{C}:$ Предприятия для частного и государственного сектора.

Совершенствованием государственного цифрового аудита Счетной палаты РФ занимается созданное в структуре подразделение программистов, которое в последующем, по словам известного финансиста А. Кудрина, «будет расширено» [Счетная палата ...].

Регламентирование цифрового аудита, а также формирование единых правил поведения и структур управления определяют средство достижения поставленных целей. Соответственно, цифровой аудит в данном случае представляет собой «средство» достижения целей. «В качестве средства явления вступают в отношениях с целью не столько в своем собственном движении и собственной жизни, сколько лишь в той связи, которая соединяет их с целями, которым они служат и по отношению к которым они как раз и определяются как средства... Средство есть не что иное, как определенность объекта через цель» [Трубников, 1968, с. 72]. В действительности соотношение государственного аудита в системе цифровой экономики, соблюдения объективности и эффективности результата не является простым механизмом. В частности, в самом индивидуальном аспекте аудита конкретного субъекта выделение целей, средств их достижения и результатов носит как частный, так и публичный характер. Однако определяющим содержание «информационного аудита», направленность системы контроля является место аудита в рассмотренной связи «цель - средство - результат».

Определим, какие существуют перспективы в развитии цифрового аудита Счетной палаты РФ.

Особое место в данном вопросе занимает основной документ, определяющий этапы развития аудита, - это «Стратегия развития Счетной палаты РФ на 2018-2024 гг.» (далее - стратегия развития) [Стратегия развития ....].

Основной компетенцией в соответствии со стратегией развития главного аудитора страны является «выступить проводником системы передовых стандартов, методов и технологий государственного управления, контроля и аудита» [Стратегия развития ...]. 
Определены следующие основные показатели цифрового аудита:

- индикатор доли аудита в деятельности;

- индикатор потенциального высокого уровня нарушений;

- индикатор востребованности выданных рекомендаций;

- индикатор общественной оценки деятельности.

Как и прежде аудит нацелен на открытость, публичность, непрерывность, эффективность, достоверность и полноту отражения данных [О счетной палате ...]. Принципы независимости, честности и ответственности должны соблюдаться всеми субъектами аудита независимо от их правового статуса.

К методике в соответствии со стратегией развития, применяемой в условиях развития цифрового аудита (информационного аудита), относятся:

- сбор и анализ плановых, первичных, текущих и отчетных данных;

- аналитические методы и мониторинг;

- прикладные методы оценки проектов и программ;

- предиктивные (прогнозные) методы аудита и значимых данных;

- дистанционные методы аудита;

- методы риск-ориентированной оценки эффективности планирования, управления, контроля и аудита;

- методы доказательного подхода влияния на результативность.

Результативность определяется с помощью проведения аудита риск ориентированного результата, направленного на взаимодействие и совершенствование информационного обмена контрольно-счетных органов субъектов и органов государственной (муниципальной) власти со Счетной палатой РФ, в целях создания единой антикоррупционной системы, повышения механизмов предотвращения правонарушений [Стратегия развития ...].

В рамках трансформации информационных систем аудита в стратегии развития [Цифровая платформа ...] определено, что необходимо создать цифровую инфраструктуру поддержки и аналитической деятельности, совершенствование процедур обратной связи, внедрить систему аналитики и поддержки принятия решения, основанных на цифровых данных.
Исходя из стратегии развития риск-ориентированного результата по итогам государственного цифрового аудита, аналитическая информация не всегда является публичной. В частности, законодатель выделяет внутренний и внешний аудит в государственном секторе [Бюджетный кодекс ...].

С точки зрения финансового менеджмента в стратегии развития информационной экономики определена одна из концепций принятия решений (американская модель) построение теории лидерства и инноваций [Современные теории менеджмента ...], в частности, организация постоянной обратной связи с сотрудниками в части определения объекта проведения государственного внутреннего и внешнего аудита [Толчинская, 2016, с. 52-52].

В целях выполнения государственных задач внутренний аудит должен основываться на использовании данных системы управления рисками для эффективного планирования работы предприятия. В отличие от внешнего аудита, нацеленного на достоверность показателей с разумной степенью уверенности, внутренний аудит должен предоставлять определенные гарантии ее достоверности в рамках ответственности за результат, что увеличивает профессиональные риски.

Анализ основных показателей применения риск-ориентированного аудита при планировании и проведении контрольных и экспертно-аналитических мероприятий за 2018 2019 гг. показали, что соотнесение проверок с социально-экономическими целями государства позволяет разработать и внедрить оценку эффективности системы стратегического управления и долгосрочных результатов. Основной целью совершенствования процедур и механизмов обратной связи является внедрение цифровой инфраструктуры аудита эффективности и стратегического аудита. Цифровая трансформация необходима не только деятельности Счетной палаты, но и всего сектора государственного управления [Отчет ..., 2018, 2019].

Организационные изменения произошли в структуре Счетной палаты РФ, в частности, созданы Департамент развития человеческого капитала, стратегического развития и цифровой трансформации (ранее автоматизации 
информационного обеспечения); введена должность стратегического аудитора.

Деятельность Департамента развития человеческого капитала связана с внедрением системы ключевых показателей эффективности деятельности, что говорит о переходе на эффективный контракт и повышении системы мотивации сотрудников. В части профессионального соответствия занимаемой должности сотрудников Счетной платы РФ разработана и апробирована модель личностных компетенций, которая позволила внедрить систему непрерывного обучения и профессионального развития, в частности, в сфере автоматизации документооборота [Отчет ..., 2018].

Работа Департамента стратегического развития связана не только с реализацией стратегических проектных направлений деятельности Счетной палаты и осуществлением внутреннего контроля деятельности и управлением документооборота, но и с мониторингом предложений по организации рабочего места сотрудников.

В рамках стратегического развития внедрен проект «Мониторинг достижения национальных целей» как единственный публичный инструмент достижения показателей. Ежемесячно публикуется дайджест, в котором содержатся данные по следующим критериям: изменение численности населения, доходов и пенсий, бедности, технологического развития и экономический рост [Аудит ...].

Стратегическое планирование аудита заключается в проведении комплексного исследования деятельности субъекта и оценки влияния объекта аудита на конечный стратегический результат. Ежегодное совершенствование методологических подходов позволит разрабатывать и применять стандарты стратегической оценки программ и проектов социально-экономической направленности. Основным критерием эффективности работы является сокращение правонарушений за счет предупредительной и профилактической работы контрольно-счетных органов по всей стране.

Целью Департамента цифровой трансформации является обеспечение маршрутизации проверок на всех уровнях федеральных, региональных государственных органов вла- сти и местного самоуправления и возможности применения корреляционного подхода в анализе данных проверок, а также использования сотрудниками единой системы данных [Отчет ..., 2018].

Раскрытие информации на портале государственного и муниципального финансового аудита (контроля) в сфере бюджетных правоотношений позволяет улучшить практику работы сотрудников. Портал представляет публичные, периодические, системные и комплексные данные проверок по объектам внешних контрольных мероприятий и принятых по ним результатов в целях обеспечения единого учета, анализа планов и результатов, что позволяет систематизировать автоматизированную работу сотрудников, а не только официально информировать на сайте.

Следует обратить внимание на проблему получения данных и взаимодействия контрольно-счетных органов, в частности, не все контрольно-счетные органы сразу получили доступ к региональным системам «Электронного бюджета» для обеспечения эффективности проведения контрольных и экспертно-аналитических мероприятий [Отчет ..., 2018].

В рамках аудита открытости публикуется рейтинг открытости органов власти в соответствии с правовой и статусной характеристикой, позволяющей оценить информационную открытость и прозрачность данных министерств, государственных корпораций и федеральных служб.

Основными способами аудита открытости является мониторинг сайтов, анализ полноты и качества опубликованных данных, тестирование качества обратной связи. По данным 2019 г. самый низкий уровень открытости информации, данных и диалога оказался у Министерства науки и высшего образования. Высокий уровень открытости по трем критериям составил у Министерства внутренних дел РФ, Министерства культуры РФ, Министерства финансов РФ и Министерства энергетики РФ. Средний показатель по критериям закрепился за Министерством иностранных дел РФ и Министерства спорта РФ [Отчет ..., 2019].

В частности, обязательна подробная публикация направлений и планов стратегического развития, планов и отчетов финансово-хозяйственной деятельности, бюджетной 
сметы и операций по целевому освоению бюджетных средств, контрольных мероприятиях и результатах проверок, а также бюджетной отчетности [Об утверждении порядка ...].

Создан новый портал-агрегатор «Государственные расходы» инструмент общественного контроля [Отчет ..., 2019], целью которого является доведение до населения открытой и прозрачной информации о планировании, получении и освоении бюджетных средств. Данный инструмент также позволяет проанализировать и определить недостатки системы государственного (муниципального) контракта.

\section{Выводы}

Подводя итоги, предлагается определить единую дефиницию «цифрового аудита» для государственного и негосударственного аудита для всех субъектов независимо от правового статуса. Под «цифровым аудитом» понимается совокупность контрольных мероприятий, направленных на выявление риск-ориентированного результата, в результате проверки обоснованных и достоверных цифровых внутренних и внешних данных. Методика и инструменты, используемые при обработке данных, являются едиными.

В настоящее время выстроенная база методологии позволяет своевременно выявлять и анализировать проблемы, формировать рациональный план проверки (выполнения работ) и эффективно распределять ресурсы, выявлять случайную ошибку исполнителя или случаи мошенничества, определять нарушения при выполнении внутренних процедур. Соответственно, результат, отражаемый в отчете о проведенной работе и актах проверок при негосударственном и государственном внутреннем аудите субъектов, является внутренней непубличной тайной таковых субъектов проверки.

Информационные платформы при сборе и обработке данных могут использоваться как единая система проведения внутреннего и внешнего цифрового аудита, так и разработанные специальные платформы для конкретных предприятий, в частности, по государственному заказу.

Соответственно, все результаты должны дополнять друг друга, что позволит выст- роить единую систему информатизации для предотвращения отрицательных последствий для всех заинтересованных субъектов, а также выполнять одну из важных миссий - совершенствовать государственное управление.

Новая форма отчетов Счетной палаты соответствует принципам понятности и доступности изложения материалов проверок, что повышает уровень доверия населения.

Прозрачность и открытость являются основными критериями раскрытия показателей объема и качества выполнения государственных (муниципальных) заданий и освоения бюджетных средств. Мониторинг и анализ показателей открытости позволяет выявить нарушения в публикационной активности на сайте органов и рекомендовать внести определенные изменения, в частности, для совершенствования критериев доступности данных и взаимодействия с населением.

Произошедшие организационные изменения в структуре Счетной палаты РФ позволяют системно взаимодействовать и уменьшать риски аудита, в частности, сократить сроки заполнения документов, обмена данными и проведения проверок. Совершенствование компетентного подхода позволит повысить персональную ответственность сотрудников Счетной палаты. Усиление обратной связи сыграет важную роль в совершенствовании взаимодействия аппарата и сотрудников, методологического подхода стратегического аудита. Для повышения эффективности работы сотрудников прежде всего необходимо внедрять систему таймменеджмент, которая позволит повысить уровень управления накопленными знаниями и практиками применения комплексного аналитического подхода к стратегическому аудиту.

Соответственно, цифровой аудит позволит своевременно и комплексно анализировать данные оценки стратегического развития и эффективность достижения результатов всех субъектов финансово-хозяйственной деятельности. Рекомендации Счетной палаты РФ по устранению и профилактике правонарушений влекут конструктивные изменения внутреннего аудита (контроля) в субъектах не только государственного, но и частного сектора по освоению бюджетных средств национальных программ и проектов стратегического развития. 


\section{СПИСОК ЛИТЕРАТУРЫ}

Бюджетный кодекс : федер. закон от 31.07.1998 № 145-Ф3 : изм. 27.12.2019 № 456-Ф3. - Доступ из справ.-правовой системы «Консультант Плюс».

О счетной палате Российской Федерации : федер. закон от 05.04.2013 № 41-Ф3 : изм. 29.05.2019 № 106-Ф3. - Доступ из справ.-правовой системы «Консультант Плюс».

Об утверждении порядка представления информации государственным (муниципальным) учреждением, ее размещения на официальном сайте в сети Интернет и ведения указанного сайта : приказ Министерства финансов от 21.07.2011 № 86н. - Доступ из справ.-правовой системы «Консультант Плюс».

Аудит национальных целей и национальных проектов. - Электрон. текстовые дан. - Режим доступа: http://www.ach.gov.ru/audit-national (дата обращения: 21.01.2020). - Загл. с экрана.

Отчет о работе Счетной палаты РФ в 2018 году. Электрон. текстовые дан. - Режим доступа: http://audit.gov.ru/promo/annual-report-2018/ index.html\#kv01 (дата обращения: 21.01.2020).Загл. с экрана.

Отчет о работе Счетной палаты РФ в 2019 году. Электрон. текстовые дан. - Режим доступа: http://audit.gov.ru/promo/annual-report-2019/ report.pdf (дата обращения: 21.01.2020).-Загл. с экрана.

Стратегия развития Счетной палаты РФ на 20182024 гг. - Электрон. текстовые дан. - Режим доступа: http://www.ach.gov.ru/about/ document/strategy-2018-2024.php (дата обращения: 21.01.2020). - Загл. с экрана.

Счетная палата перейдет на цифровой аудит в течение трех лет. - Электрон. текстовые дан. - Режим доступа: https://tass.ru/ekonomika/5423538 (дата обращения: 21.01.2020). - Загл. с экрана.

Современные теории менеджмента. Стратегии лидерства и инноваций. - Электрон. текстовые дан. - Режим доступа: https://scienceproblems. ru/sovremennye-teorii-menedzhmenta-strategiiliderstva-i-innovatsij/2.html (дата обращения: 21.01.2020). - Загл. с экрана.

Толчинская, М. Н. Развитие государственного аудита в Российской Федерации / М. Н. Толчинская, Л. А. Ахмедова // Международный бухгалтерский учет. Финансы и кредит. - 2016. № 9. - С. 51-52.

Трубников, Н. Н. О категориях «цель», «средство», «результат» / Н. Н. Трубников. - М. : Высш. шк., 1968. - 148 c.

Федорцова, В. А. Финансовый контроль и аудит: теория и практика эффективного применения в России / В. А. Федорцова // Финансовый контроль в сфере публичных и частных финансов : материалы Междунар. науч.-практ. конф. (г. Москва, 25 ноября 2016 г.) / под ред. И. А. Цинделиани. - М. : РГУП, 2017. - 66 с.

Цифровая платформа Счетной палаты Российской Федерации. - Электрон. текстовые дан. - Режим доступа: https://globalcio.ru/live/projects/3135 (дата обращения: 21.01.2020). - Загл. с экрана.

\section{REFERENCES}

Byudzhetnyy kodeks: feder. zakon ot 31.07.1998 № 145FZ: izm. 27.12.2019 № 456-FZ [Budget Code. Federal Law of July 31, 1998 no. 145-FZ. Amended on December 27, 2019 no. 456-FZ]. Access from Reference Legal System "KonsultantPlyus".

O schetnoy palate Rossiyskoy Federatsii: feder. zakon ot 05.04.2013 № 41-FZ: izm. 29.05.2019 № 106-FZ [On the Accounts Chamber of the Russian Federation: federal. Law dated 04/05/2013 No. 41FZ: amend. 05/29/2019 No. 106-FZ]. Access from Reference Legal System "KonsultantPlyus".

$\mathrm{Ob}$ utverzhdenii poryadka predstavleniya informatsii gosudarstvennym (munitsipalnym) uchrezhdeniem, ee razmeshcheniya na ofitsialnom sayte $\mathrm{v}$ seti Internet i vedeniya ukazannogo sayta: prikaz Ministerstva finansov ot 21.07.2011 № 86n [On the Approval of the Procedure for the Submission of Information by a State (Municipal) Institution, Its Placement on the Official Website on the Internet and Maintaining the Specified Site. Order of the Ministry of Finance of July21, 2011 no. 86n]. Access from Reference Legal System "KonsultantPlyus".

Audit natsionalnykh tseley $i$ natsionalnykh proektov [Audit of National Goals and National Projects]. URL: URL: http://www.ach.gov.ru/audit-national/ (accessed 21 January 2020).

Otchet o rabote Schetnoy palaty RF v 2018 godu [Report on the Work of the Accounts Chamber of the Russian Federation in 2018]. URL: URL: http:/audit.gov.ru/ promo/annual-report-2018/ index.html\#kv01 (accessed 21 January 2020).

Otchet o rabote Schetnoy palaty $R F v 2019$ godu [Report on the Work of the Accounts Chamber of the Russian Federation in 2019]. URL: URL:http://audit.gov.ru/promo/annual-report2019/report.pdf(accessed 21 January 2020).

Strategiya razvitiya Schetnoy palaty $R F$ na 2018 $2024 \mathrm{gg}$. [Development Strategy of the Accounts Chamber of the Russian Federation for 20182024]. URL: http://www.ach.gov.ru/about/ document/strategy-2018-2024.php (accessed 21 January 2020). 


\section{ФИНАНСЫ. БУХГАЛТЕРСКИЙ УЧЕТ}

Schetnaya palata pereydet na tsifrovoy audit $v$ techenie trekh let [The Accounts Chamber Will Switch to Digital Audit Within Three Years]. URL: https://tass.ru/ekonomika/5423538 (accessed 21 January 2020).

Sovremennye teorii menedzhmenta. Strategii liderstva i innovatsiy [Modern Management Theory. Leadership and Innovation Strategies]. URL: https://scienceproblems.ru/sovremennyeteorii-menedzhmenta-strategii-liderstva-iinnovatsij/2.html (accessed 21 January 2020).

Tolchinskaya M.N., Akhmedova L.A. Razvitie gosudarstvennogo audita v Rossiyskoy Federatsii [The Development of State Audit in the Russian Federation]. Mezhdunarodnyy bukhgalterskiy uchet. Finansy i kredit [International Accounting. Financeand Credit], 2016, no. 9, pp. 51-52.

Trubnikov N.N. O kategoriyakh "tsel», "sredstvo», «rezultat»[About the Categories "Goal",
"Means", "Result"]. Moscow, Vysshaya shkola Publ., 1968. 148 p.

Fedortsova V.A. Finansovyy kontrol i audit: teoriya i praktika effektivnogo primeneniya $\mathrm{v}$ Rossii [Financial Control and Audit: Theory and Practice of Effective Application in Russia]. Tsindeliani I.A., ed. Finansovyy kontrol v sfere publichnykh $i$ chastnykh finansov: materialy Mezhdunar. nauch.-prakt. konf. (g. Moskva, 25 noyabrya 2016 g.) [Financial Control in the Field of Public and Private Finance: Proceedings of the International Scientific and Practical Conference (Moscow, November 25, 2016)]. Moscow, RGUP, 2017. 66 p.

Tsifrovaya platforma Schetnoy palaty Rossiyskoy Federatsii [Digital Platform of the Accounts Chamber of the Russian Federation]. URL: https:// globalcio.ru/live/projects/3135/ (accessed 21 January 2020).

\section{Information About the Author}

Varvara A. Fedorcova, Senior Lecturer, Department of Finance, Financial Law, Economics and Accounting, Petrozavodsk State University, Prosp. im. V.I. Lenina, 33, 185910 Petrozavodsk, Russian Federation, fealva@mail.ru,https://orcid.org/0000-0002-1308-4552

\section{Информация об авторе}

Варвара Александровна Федорцова, старший преподаватель кафедры финансов, финансового права, экономики и бухгалтерского учета Института экономики и права, Петрозаводский государственный университет, просп. им. В.И. Ленина, 33, 185910 г. Петрозаводск, Российская Федерация, fealva@mail.ru, https://orcid.org/0000-0002-1308-4552 